\title{
Effect of amygdaloid complex inhibition on nicotine-induced conditioned place preference in rats
}

\author{
Sara Sadeghi-Gharajehdaghi ${ }^{1}$, Hedayat Sahraei $^{2}$, Zahra Bahari $^{3}$, Gholam Hossein Meftahi $^{2}$, Gila Pirzad Jahromi ${ }^{2}$, \\ Hengameh Ali-Beik ${ }^{1}$ \\ ${ }^{1}$ Department of Biology, Faculty of Science, Islamic Azad University, North Tehran Branch, Tehran, Iran. \\ ${ }^{2}$ Neuroscience Research Center, Baqiyatallah University of Medical Sciences, Tehran, Iran. \\ ${ }^{3}$ Department of Physiology and Biophysics, Faculty of Medicine, Baqiyatallah University of Medical Sciences, Tehran, Iran
}

\section{ARTICLE INFO \\ Article history: \\ Received on: 09/11/2016 \\ Accepted on: 10/02/2017 \\ Available online: 30/03/2017}

\section{Key words:}

Amygdaloid Complex;

Compartment crossing;

Lidocaine; Nicotine;

Rearing; Sniffing; Rat.

\begin{abstract}
Nicotine dependence is the major cause of cigarette smoking. The dependence occurred in the brain mesolimbic system and the amygdala has an important role in its initiation. Nicotine can activate dopaminergic neurons within the amygdaloid complex However, there is no evidence about complete inhibition of amygdala on nicotine dependence, thus in the present study we used conditioned-place preference (CPP) method to study the effect of transient inhibition of left and/or right side of the amygdala by lidocaine on nicotine reward properties in male Wistar rats. One week after two side cannulation and recovery the rats were conditioned to nicotine. Lidocaine hydrochloride (2\%) was injected in amygdaloid complex, five min before each nicotine intraperitoneal (IP) injection for transient inhibition. On the test day, the animals were placed in the apparatus and their behaviors were recorded by a camera for 600 seconds. Then the records were analysis off line for sniffing, rearing, locomotion and compartment crossing. Three-way analysis of variance (ANOVA) was performed for statistical analysis. Our results showed that intra-peritoneal injection of nicotine (1 and 1.5 $\mathrm{mg} / \mathrm{kg}$ ) induced place preference. Transient inhibition of left or /and right side of the amygdaloid complex reduces nicotine place conditioning. In addition, rearing and compartment crossing also were reduced. However, when left side of the nucleus was inhibited, sniffing was increased, but when the right side was inhibited the sniffing was decreased. In conclusion, these results confirmed the involvement of both left and right sides of the amygdaloid complex in nicotine place conditioning.
\end{abstract}

\section{INTRODUCTION}

Smoking remains the one of the most serious cause of death in the developed countries (Peto et al., 1992). Nicotine, the major neuroactive component in tobacco, is a potently addictive substance in humans and other animal (Dalack et al., 1998). Despite a lot of studies have been made in illuminating the neuropharmacological and neuroanatomical effects of nicotine, the precise neural system for the rewarding and addictive

\footnotetext{
* Corresponding Author

Dr. G. H. Meftahi, Neuroscience Research Center, Baqiyatallah

University of Medical Sciences, Telfax: (9821)26127286,

POBox: 19395-6558,Tehran, Iran.Email: hossein.meftahi @ bmsu.ac.ir
}

properties of nicotine has not been identified. It has been shown that the mesolimbic dopamine (DA) pathway, which originates from DA cell bodies in the ventral tegmental area (VTA) and projects to the amygdaloid complex, may be involved in mediating the rewarding effects of nicotine. For instance, lesions of the mesolimbic system or administration of DA receptor antagonists reduce nicotine self-administration in rodents (Corrigall and Coen, 1991; Dani, 2003). The amygdala complex consists of numerous nuclei deep into the middle temporal lobe and comprises part of the limbic system. It is interconnected with many regions of the nervous system and induces a number of behaviors in animals (Campeau and Davis, 1995). Basolateral nucleus, as well as the cortical and the central nuclei, are connected to many cerebral structures such as the frontal cortex, the prefrontal cortex and the 
hippocampus, contributing to the integrity of behavior, stress and reward circuits (Mosher et al., 2010). Thus, it appears that these nuclei may be involved in reward behaviors of addictive drugs (Kelley and Berridge, 2002). In addition, studies also showed that the amygdala may be involved in the responses to stress and its function changes by stress as well (Asalgoo et al., 2015; Dalooei et al., 2016; Ghobadi et al., 2016; Mohammadian et al., 2016; Ehteram et al., 2017). Previous studies have indicated that LArginine, a precursor of nitric oxide, reinforces the role of morphine in inducing conditioned place preference in the central nuclei of the amygdala. Furthermore, administering L-NAME (LNitro-Arginine Methyl Ester), an inhibitor of nitric oxide synthetase, suppresses the function of morphine in inducing conditioned place preference (Zarrindast et al., 2002; Bahari et al., 2014; Bahari et al., 2015). These findings showed the effect of the central nucleus of the amygdala on morphine-induced place conditioning. In addition, $\mathrm{D}_{1}$ and $\mathrm{D}_{2}$ dopamine receptors are involved in inhibition and stimulation of conditioned place preference induced by morphine ( Esmaeili et al., 2012). It has been shown that nicotine can affect the performance of different parts of the amygdala. For instance, Kobiella et al. (2011) showed that administering of nicotine in non-smokers, leading to increased neural activation and anxiety elicited by unpleasant stimuli as well as changed connectivity within the amygdala-pACC circuit. Moreover, it has been established that smoking induces stress behaviors or reinforces these behaviors in different people. According to Kupferschmidt et al. (2010), these behaviors may be age-related. Also, Bergstron et al. (2010) indicated that administering $0.5 \mathrm{mg} / \mathrm{kg}$ nicotine three times a week over a period of two weeks causes intensive changes in morphology and dendritic ramification pattern in the baso-lateral region of the amygdala. Pascual et al. (2009) showed that a significant increase of pCREB and Fos protein expression occurs in the amygdala and some other regions of rat brains during nicotine preference and reinstatement behaviors. Thus, high-level expression of these proteins is related to be an effect of nicotine in inducing learning and memory. Furthermore, synaptic potentiation in structures normally associated with memory may participate in nicotine dependence (Hyman, 2005; Hyman et al., 2006). Di Chiara and Imperato (1988) showed that nicotine administration increase extracellular dopamine by stimulating the firing of dopaminergic neurons, which showed the rewarding properties of nicotine in limbic system.

Also, it has been shown that nicotine increase burst activity in dopamine neurons, which is associated with basic motivational processes underlying learning, and cognitive behavior (Nisell et al., 1995). However, the role of the amygdala complex in the nicotine function is not clear and also the role of this nucleus in nicotine response in conditioned place preference is controversial. Considering the intricate nature of the amygdala complex, as well as the fact that studying the different regions of amygdala separately cannot be very accurate in yielding an understanding the role of the amygdala in nicotine function. Therefore in this study, we used lidocaine to inhibit amygdala temporarily in order to evaluate its role in nicotine-induced conditioned place preference. Moreover, several dopamine-related behaviors including locomotion, rearing and sniffing were investigated.

\section{MATERIAL AND METHODS}

\section{Animals}

Male Wistar rats (250-280 g, Pasture Institute, Tehran, Iran) were used throughout the study ( 8 rats for each group). Animals were housed in twelve groups of eight rats per cage with a 12/12 h light-dark cycle, with ad-lib food and water available. The animals were randomly allocated to different groups of the experiment. All experiments were conducted in accordance with standard ethical guidelines and approved by the local ethical committee (The Baqiyatallah University of Medical Committee on the Use and Care of Animals, 81/021, July 10, 2002).

\section{Drugs}

The following drugs were used in these experiments: nicotine hydrogen tartrate (Tocris, UK), lidocaine hydrochloride (Sigma, USA), ketamine hydrochloride and xylazine (Alfasan Worden, Holland). All drugs were dissolved in physiologic saline $(0.9 \%)$ just before the experiments.

\section{Surgical procedures}

Rats were anesthetized with Ketamine hydrochloride (70 $\mathrm{mg} / \mathrm{kg}$, i.p. $)+$ Xylazine $(10 \mathrm{mg} / \mathrm{kg}$, i.p. $)$ and one or two stainless steel cannulas (23-gauge) were placed stereotaxically into the left or right or both sides of the amygdala. Stainless steel, 23-gauge guide cannulas were implanted bilaterally $0.5 \mathrm{~mm}$ above the intended site of injection according to the atlas of Paxinos and Watson (Paxinos and Watson, 1987). Stereotaxic coordinates for the amygdala were: $\mathrm{AP}=-2 / 3 \mathrm{~mm}, \mathrm{ML}=4 / 4 \mathrm{~mm}, \mathrm{DV}=6 / 2 \mathrm{~mm}$. Cannulas were secured to jewelers' screws with dental acrylic. After completing the surgery, a dummy inner cannula was inserted into the guide cannula and left in place until injections were made. The length of the dummy cannula matched with the guide cannula. Animals were allowed seven days to recover from surgery and anesthesia. For drug infusion, the animals were gently restrained by hand; the stylets were removed from the guide cannulas and replaced by 30 -gauge injection needles $(0.5 \mathrm{~mm}$ below the tip of the guide cannula).

Nicotine was intraperitoneal (i.p.) injected in a volume of $1.5 \mathrm{ml} / \mathrm{kg}$, while 2\% lidocaine (Pontieri et al., 1996; Hosseini et al., 2015) was given intra-amygdala in a volume of $1.0 \mu \mathrm{l} / \mathrm{rat}(0.5$ $\mu l$ in each side) five min before the nicotine injection. Injected needles were left in place for an additional $60 \mathrm{~s}$ to facilitate diffusion of the drugs. The effect of lidocaine as a reversible $\mathrm{Na}^{+}-$ channel blocker is the greatest around $8 \mathrm{~min}$ after infusion and may last for up to $30 \mathrm{~min}$. Since the time of action for lidocaine is around $30 \mathrm{~min}$, this time is good interfaced by the action of nicotine (10-25 min) (Meredith, 1999). The control groups received saline. 


\section{Animals groups}

Four group of animals for three days received different doses of nicotine $(0.1,0.5,1.0$, or $1.5 \mathrm{mg} / \mathrm{kg}$, i.p. $)$. One group only received saline and three groups received saline + lidacaine $(0.5$ $\mu \mathrm{l} / \mathrm{side}$ ) in left, right or both side of the amygdala. One group received saline+ nicotine $(1.5 \mathrm{mg} / \mathrm{kg})$ and three other groups received saline+lidacaine $(0.5 \mu \mathrm{l} / \mathrm{side})+$ nicotine $(1.5 \mathrm{mg} / \mathrm{kg})$ in left, right or both side of the amygdala.

\section{Apparatus}

A two compartment place preference apparatus $(30 \times 60$ $\times 30 \mathrm{~cm}$ made of wood) was used in the experiments (ChalabiYani et al., 2015). Both compartments were identical in size (the apparatus was divided into two equal-sized compartments by means of a removable white guillotine door) and shading (both were white), but distinguishable by texture, olfactory and visual cues. To provide the tactile difference between the compartments, one of the compartments had a smooth floor, while the other compartment had a nylon white mesh floor. A drop of menthol was placed at the right center of the compartment with a textured (nylon mesh) floor, to provide the olfactory difference between the compartments.

For visual differences, the compartments were differently striped black on their sides. In this apparatus, rats showed no consistent preference for either compartment, which supports our un-biased place conditioning paradigm.

\section{Behavioral testing \\ Measurement of conditioned place preference}

Conditioned place preference consisted of three phases: pre-conditioning, conditioning and post conditioning. Place conditioning was conducted using an unbiased procedure, with minor changes to the design as previously described (Chalabi-Yani et al., 2015).

\section{Pre-conditioning}

On day 1 (pre-exposure), each rat was placed separately into the apparatus for $10 \mathrm{~min}$, with free access to all compartments and the time spent by rats in each compartment was measured. Our data showed that the animals did not show any consistent preference for either compartment (data not shown).

\section{Conditioning}

This phase consisted of a 3-day schedule of conditioning sessions. In this phase, animals received three trials in which they experienced the effects of the nicotine while confined in one compartment for $45 \mathrm{~min}$ and three trials in which they experienced the effects of saline while confined in the other compartment for $45 \mathrm{~min}$. Access to the other compartments was blocked on these days. In addition, nicotine and saline compartments were randomly assigned for each animal in a counterbalanced way. Five min before each nicotine injection, lidocaine $2 \%$ was injected in the left and / or right side of amygdala according to the experimental procedure.

\section{Post conditioning phase}

On the 5th day (the preference test day) the partition removed, and each rat was placed in the middle part of the apparatus where it could access the entire compartments. The behavior of each animal was digitally videotaped for $10 \mathrm{~min}$. Video files were later analyzed off line by a person who was not familiar with the experiments. Two stereotyped behaviors- sniffing and rearing-, and one non-stereotyped behavior compartment crossing (the total crossing between the compartments, which can be considered as a good indicator of locomotor activity, in addition to the total time which animal spent in each compartment) were distinguished.

After the completion of testing, all animals were anesthetized and received a transcardiac perfusion with $0.9 \%$ normal saline followed by $10 \%$ buffered formalin. The brains were removed, blocked and cut coronally in $40 \mu \mathrm{m}$ sections through the cannula placements. The tissues were stained with cresyl violet and were examined by light microscopy by an unfamiliar observer to the behavioral data. Only the animals with correct cannula placements were included in the data analysis (Fig. $1)$.

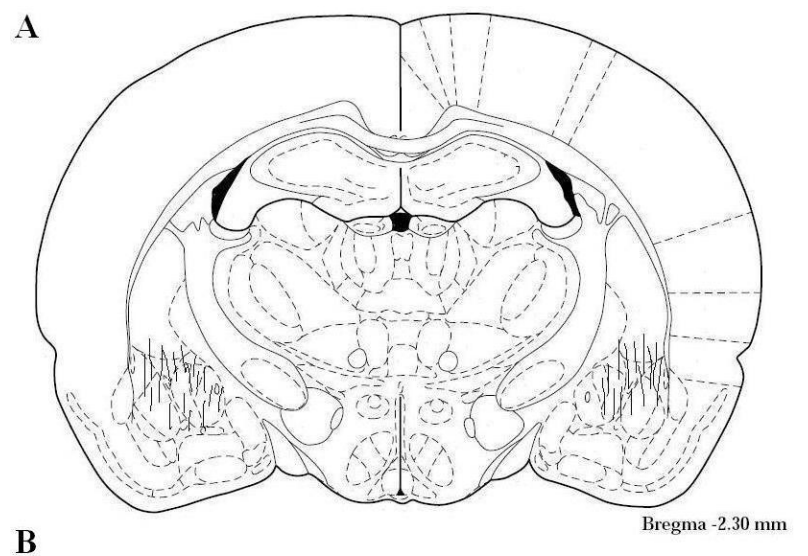

B

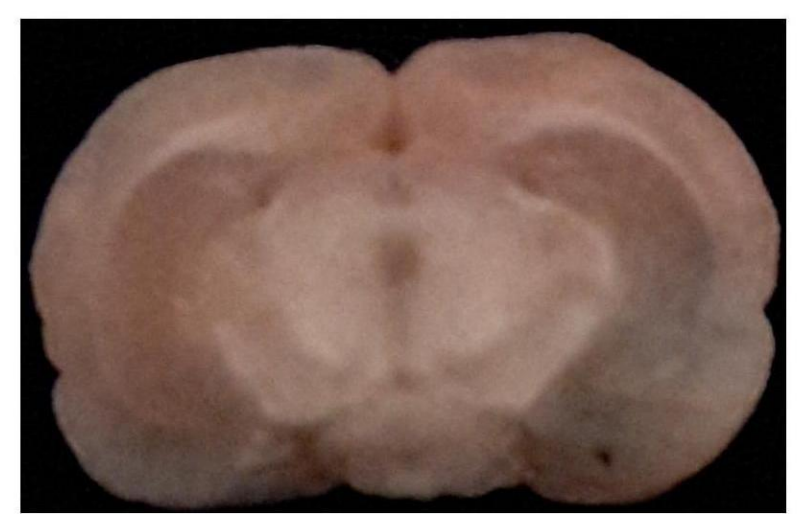

Fig. 1: Location of the cannula tips in the amygdala according to the atlas of Paxinos and Watson (A) and real histological approval of the cannula placement (B).

\section{Data Analysis}

All data expressed as mean \pm S.E.M. Nicotine doseresponse was analyzed using one-way analysis of variance 
(ANOVA) followed by Tukey post hoc. A three-way analysis of variance (ANOVA) was applied for the analysis the differences between the lidocaine treated groups using side, pretreatment and treatment as factors. When three-way analysis of variance showed a significant difference, the Tukey HSD test was applied to demonstrate the difference. Differences with $\mathrm{P}<0.05$ were considered as significant.

\section{RESULTS}

\section{Effect of nicotine on induction CPP}

Animals for three days received different doses of nicotine $(0.1,0.5,1.0$, or $1.5 \mathrm{mg} / \mathrm{kg}$, i.p.). The results showed that application of 1 and $1.5 \mathrm{mg} / \mathrm{kg}$ nicotine are able to significantly induce CPP than the group receiving saline Fig. $2((\mathrm{~F}[5,33]=$ $2.91, \mathrm{P}<0.001)$ ). Investigating of dopamine behavior showed that nicotine injection increased number of sniffing $(\mathrm{F}[4,23]=4.329$, $\mathrm{P}<0.01)$ and total compartment crossing at a dose of 0.1 and 0.5 $\mathrm{mg} / \mathrm{kg}$ and at a higher dose $(1,1.5 \mathrm{mg} / \mathrm{kg})$ reduced sniffing and total compartment crossing $(\mathrm{F}[4,25]=2.25, \mathrm{P}<0.05)$ (fig. $3 \mathrm{~A}$, B). In addition, nicotine significantly reduced number of rearing at different doses than the group received saline $(\mathrm{F}[5,35]=4.12, \mathrm{P}<$ 0.01) (fig. 3 C).

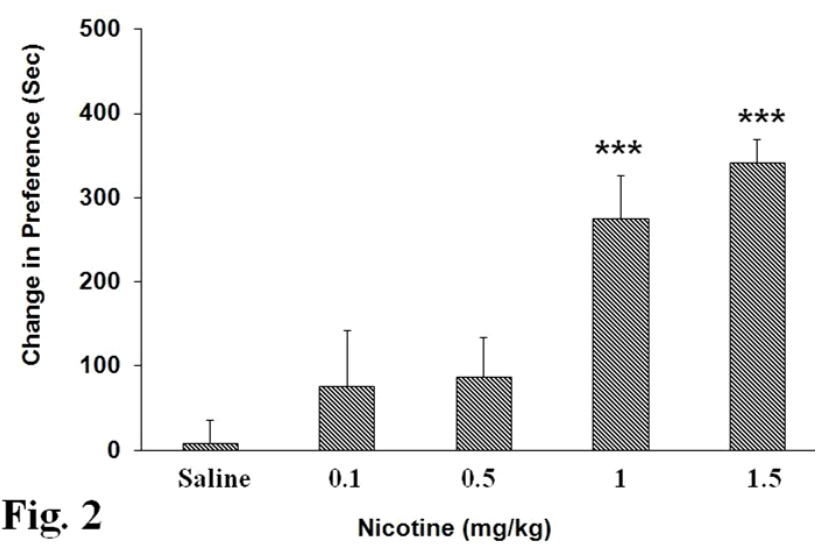

Fig. 2: Dose dependence of place conditioning preference induced by nicotine. changes in preference, sec. Means \pm SEM for 8 rats are shown. *** Significant differences from the saline control group, $\mathrm{P}<0.001$.

A

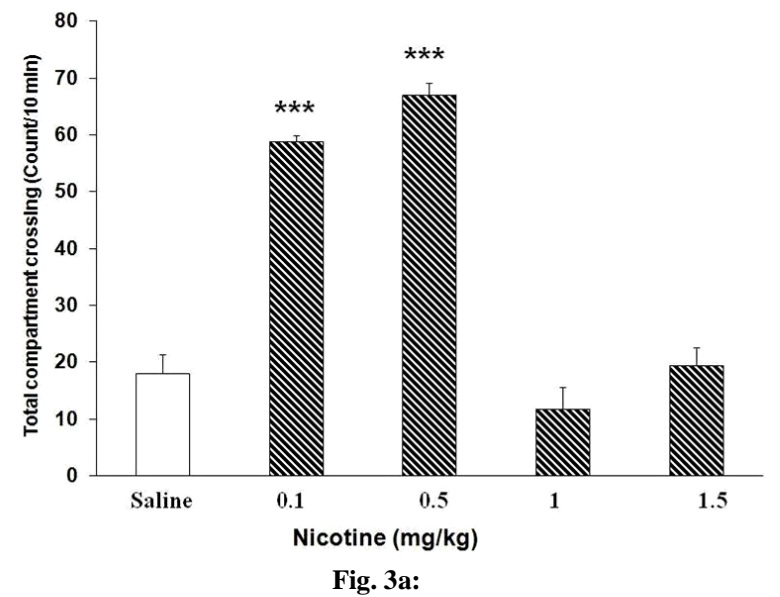

B
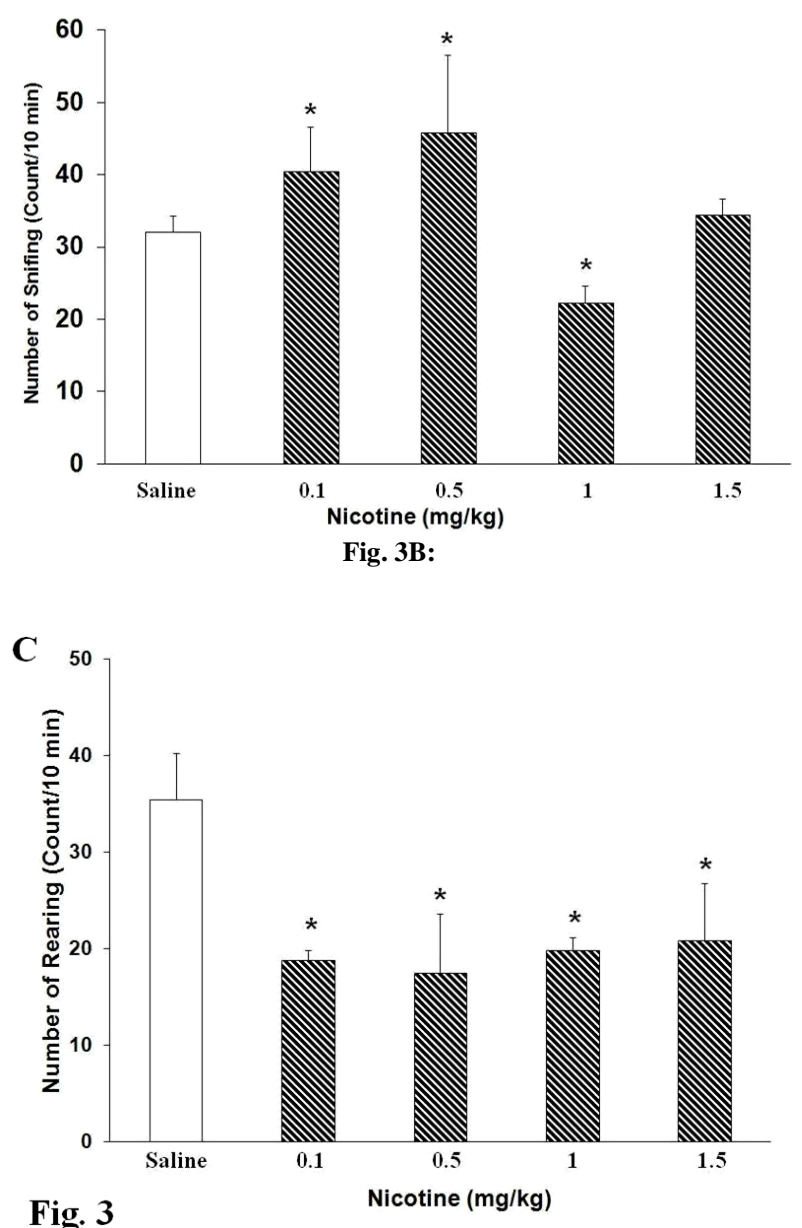

Fig. 3C:

Fig. 3: Effects of different doses of nicotine on place preference and dopaminerelated behaviors in rats. Effects of different doses of nicotine on total compartment crossing (A) number of sniffing (B) and number of rearing (C). Animals received nicotine $(0.1,0.5,1$, and $1.5 \mathrm{mg} / \mathrm{kg}$, IP). Each point represents the mean \pm SEM of conditioning score for 8 rats, $* \mathrm{P}<0.05$, $* * * \mathrm{P}<$ 0.001 different from the saline control group.

\section{The inhibitory effect of unilateral or bilateral amygdala on nicotine-induced CPP}

The present results showed that place preference for a drug-paired compartment demonstrated no significant changes when the right or left side of the amygdala was inhibited by lidocaine. But an injection of lidocaine before nicotine administration into left or right or both sides of the amygdala significantly reduced place preference [Three-Way ANOVA within-group comparison: Side effect: $\mathrm{F}(5,35)=0.76, \mathrm{P}>0.05$, Pretreatment effect: $\mathrm{F}(1,32)=1.14, \mathrm{P}>0.05$, Treatment effect: $\mathrm{F}(5,32)=3.21, \mathrm{P}<0.01$, Side $\times$ Pretreatment $\times$ Treatment effect: $\mathrm{F}(8,71)=4.42, \mathrm{P}<0.001$ ] (Fig. 4 A). (fig. 4 A). Moreover, total compartment crossing in all groups which lidocaine injection into left or right or both sides of amygdala before nicotine injection was reduced in comparison with the control significantly (Threeway ANOVA within group comparison: side effect: $\mathrm{F}[5,35]=$ 3.24, $\mathrm{P}<0.01$, pretreatment effect: $\mathrm{F}[1,35]=3.14, \mathrm{P}<0.01$, treatment effect: $\mathrm{F}[4,31]=4.03, \mathrm{P}<0.01$, side $\times$ pretreatment $\times$ treatment effect: $\mathrm{F}[8,73]=5.45, \mathrm{P}<0.001]$ ) (fig .4 B). 
A

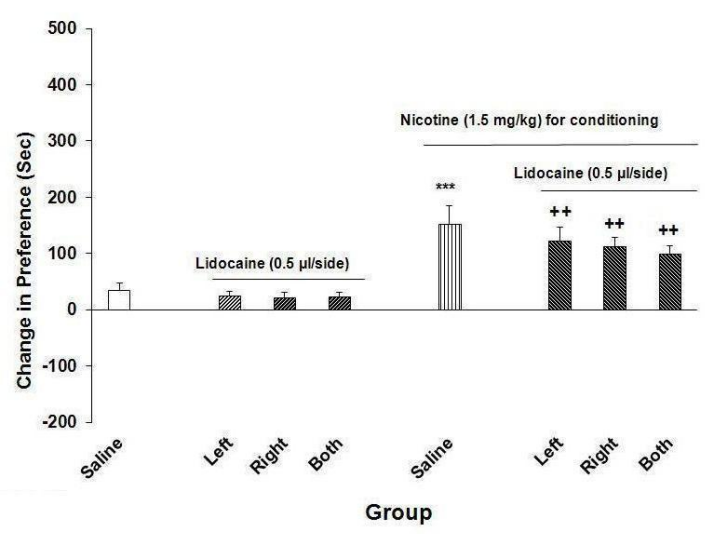

C

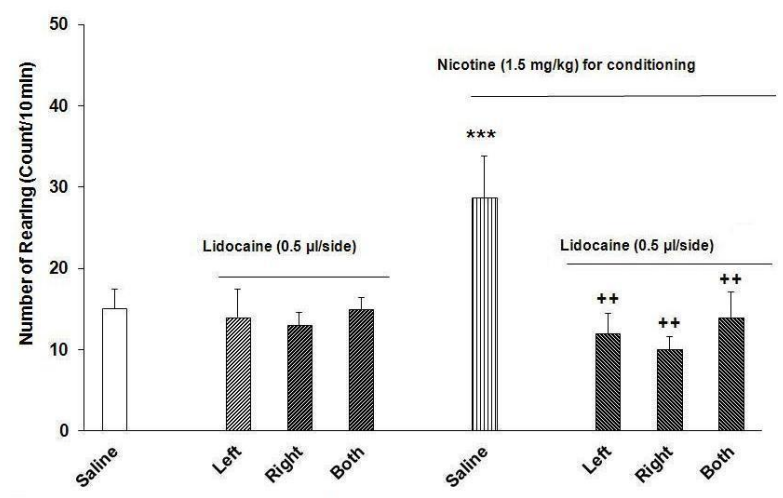

Fig. 4

Group
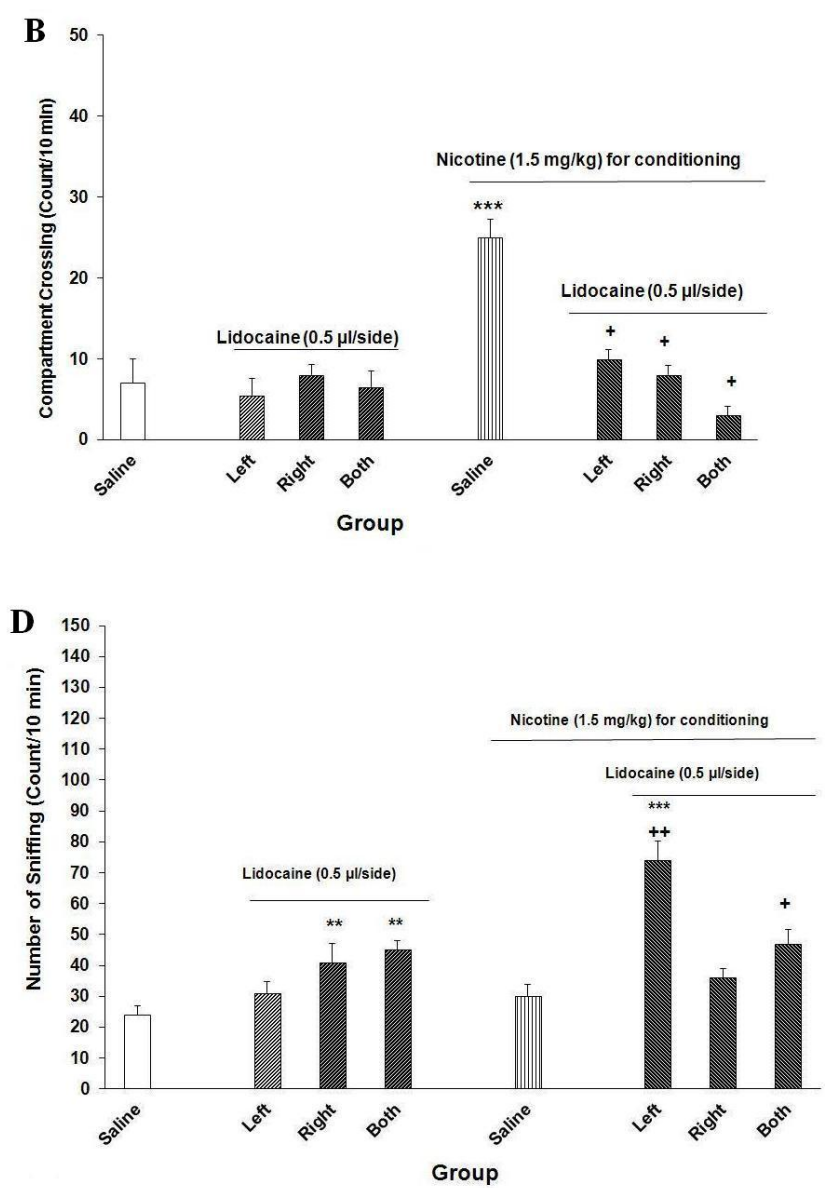

Fig. 4: Effects of left or / and right side inhibition of amygdala on nicotine place preference. Animals received lidocaine into their amygdala before nicotine (1.5 $\mathrm{mg} / \mathrm{kg}, \mathrm{IP})$, or saline $(1 \mathrm{ml} / \mathrm{kg})$ in each conditioning sessions. Injection of lidocaine in the right, left, or both sides of the amygdala cannot inhibit nicotine-induced place preference (A). Each point shows the mean \pm SEM of conditioning score for 8 rats. ${ }^{*} P<0.05$, ${ }^{* * * *} P<0.00$ indicate differences with the saline control group Inhibition of amygdala in compartment crossing (B). In addition, the number of rearing (C) and sniffing (D) also showed in the animals. Each point shows the mean \pm SEM of the behavior for 8 rats. ${ }^{* * * *} P<0.001,{ }^{* *} P<0.01,{ }^{*} P<0.05$ are different from the saline control group and ${ }^{+++} P<0.001,{ }^{++} P<0.01,+P<0.05$ different from lidocaine control group.

Inhibition of the right or left side or both parts of amygdala couldn't significantly change the number of animals rearing than the control group. But before the injection of the nicotine inhibition of the right or left side or both parts of amygdala significantly reduced the number of animals rearing in the nicotine-induced place preference in the rats (Three-way ANOVA within-group comparison: side effect: $\mathrm{F}[5,28]=1.18, \mathrm{P}$ $>0.05$, pretreatment effect: $\mathrm{F}[1,30]=0.86, \mathrm{P}>0.05$, treatment effect: $\mathrm{F}[5,35]=1.35, \mathrm{P}<0.05$, side $\times$ pretreatment $\times$ treatment effect: $\mathrm{F}[8,67]=3.36, \mathrm{P}<0.01)$ (fig .4 C).

In relation to number of sniffing, the behavior increased when right or both sides of amygdala inhibited and suppression of left side has no effect in sniffing. Inhibition of left side or both sides of the amygdala by lidocaine before nicotine administration significantly increased number of sniffing than the control group, but inhibition of the right side couldn't change the number of sniffing significantly [Three-Way ANOVA within-group comparison: Side effect: $F(5,35)=4.17, \mathrm{P}<0.001$, Pretreatment effect: $\mathrm{F}(1,35)=3.53, \mathrm{P}<0.01$, Treatment effect: $\mathrm{F}(5,35)=3.87$, $\mathrm{P}<0.01$, Side $\times$ Pretreatment $\times$ Treatment effect: $\mathrm{F}(8,73)=4.11$, $\mathrm{P}<0.01$ ] (fig .4 D).

\section{DISCUSSION}

This study set out with the aim of assessing the function of amygdala with regard to the effects of nicotine and we investigated the relationship between the amygdala and the pleasurable effects of nicotine. To investigating the effect of temporary inhibition of amygdala on conditioned place preference, we evaluated dopamine-dependent behaviors such as sniffing, rearing and locomotion in animals. Our findings indicate that administering nicotine, according to the protocol described by Shoaib et al. (1994) and Shoaib (1997) in dose-dependent manner induce conditioned place preference in rats, which is consist with previous studies. Also, Yararbas et al. (2010) reported the nicotine induced conditioned place preference in rats. 
A number of studies have been conducted about the effects of nicotine on dopamine-dependent behaviors such as sniffing, rearing and locomotion (Gray and Joseph, 1997, Motahari et al., 2016). Previous studies indicate that administering nicotine may yield different behaviors; however, all these studies have assessed the animals immediately after administration whereas our study poses an interval of 24 hours between the last administration and evaluation. Administering of nicotine increased locomotion at lower doses and decreased locomotion at higher doses, which means nicotine is involved in inducing locomotion even as long as 24 hours after discontinuation. The function of nicotine in inducing locomotion at lower doses and suppressing locomotion at higher doses after a delay period of 24 hour is first reported in this study and thus requires further studies for clarification. Results also indicate that sniffing (a dopamine-dependent behavior and an indicator of the response of dopamine system to nicotine) increased at lower doses of nicotine and decreased significantly at higher doses of nicotine. This is in line with our previous finding (Hosseini et al., 2015) and indicates that administering nicotine may affect dopamine-dependent behaviors even as long as 24 hours after the nicotine is discontinued, which confirms the longterm effects of nicotine after discontinuation. Furthermore, the rearing behavior, decreased in the nicotine group; however, this decrease was statistically significant at all doses of nicotine. This indicates that administering nicotine may affect the dopaminedependent behaviors in the long-term. Previous studies indicated that administering nicotine may increase expression of different genes in various areas of the nervous system such as the ventral tegmentum, nucleus accumbens and amygdala (Li et al., 2004; Kane et al., 2005). The importance of dopamine-dependent behaviors is that they indicate the activity of the dopamine mesolimbic system. It appears that conditioned place preference entails a decrease in the activity of the dopamine mesolimbic system, which is in line with previous studies. Ito and Hayen (2011) demonstrated that reward behaviors in rats are related to increased dopamine in the shell part of the nucleus accumbens and decreased dopamine in the central region of the nucleus. Since dopamine-dependent behaviors are integrated in the central region of the nucleus accumbens, the decreased dopamine is consistent with the decrease in dopamine-dependent behaviors, as seems to be the case in our study, as well. Nevertheless, it has been indicated that a direct relationship between the central region of the amygdala and nicotine dependence (Salín-Pascual and Basañez-Villa, 2003). Considering the fact that different effects of nicotine have been shown in animals, the effects of nicotine are related to species, age, gender, previous history of receiving nicotine, and genetic factors (Neal et al., 2009).

In the other part of present study our results showed that unilateral or bilateral temporary inhibition of the amygdala by lidocaine has contributed on nicotine-induced conditioned place preference. In other words, the amygdala plays a pivotal role in the pleasurable effects of nicotine. Administering of lidocaine to left, right or both sides of amygdala decreased nicotine-induced conditioned place preference; however, is not significant. Thus, it seems that although unilateral (left or right) or bilateral inhibition of amygdala yields a slight decrease in nicotine efficiency, but it couldn't suppress the effects of nicotine completely. In addition, administering lidocaine cannot induce conditioned place preference. However, it must be noted that in our study, although unilateral or bilateral inhibition of amygdala couldn't suppress conditioned place preference significantly, but it managed to reduce it to some extent. In this regard, White et al. (2005) indicated that amygdala damage may disrupt in morphine-induced place preference in rats. This disruption indicates the effect of addictive drugs in inducing different types of memory mediated by the amygdala (Holland and Gallagher, 2003). Thus, the amygdala is considered involved in the learning process of conditioned place preference and it may not be greatly involved in the motivation part.

The activity of animals decreased in all groups treated with lidocaine compared to the group receiving nicotine. This indicates the impact of the amygdala (left, right and both sides) on the locomotive behavior induced by nicotine; in other words, administering nicotine induces locomotive behavior in animals and this behavior decreases in the groups receiving lidocaine. Thus the amygdala suppression decreases the locomotion of animal without affecting the reward responses of nicotine. Therefore, inhibiting the amygdala may affect the animal locomotion without affecting the reward behaviors.

However, other studies indicate that conditioning the animal with food has a direct relationship with the rise of acetylcholine in amygdala (Carrere and Alexandre, 2015). Vlachou and Markou (2010) indicated that suppressing the amygdala with muscimol (an agonist of GABA-a receptor) before training or before a test (acquisition and expression of conditioning) may inhibit food-induced conditioning, whereas administering the drug after training fails to inhibit conditioning. In addition, electrical kindling of the amygdala induces conditioned place aversion in rats (Ripley et al., 2002). It has been demonstrated that administering naloxone into the central region of the amygdala induces conditioned place aversion in morphine-dependent rats, indicating the direct role of the amygdala (particularly the extended amygdala region) in place aversion in addicted rats conditioned with morphine (Zarindast and Rezayof, 2007). Moreover, administering amphetamine or cocaine to the basolateral region of amygdala failed to induce conditioned place preference/aversion in animals, while administering amphetamine into the central region of amygdala induced a strong conditioned place preference in rats (Vollm, 2004). Additionally, administering agonists and antagonists of dopamine, as well as GABAergic and cholinergic drugs into different regions of the amygdala yielded no effects (Dixon and Prior, 2005). Hsu et al. (2002) demonstrated that administering bupivacaine (a topical anesthetic agent) into the basolateral region of amygdala suppresses the conditioned place preference caused by amphetamine. A similar effect is observed with scopolamine, while administering agonists and antagonists of D1 and D2 dopamine receptors into the central region of amygdala resulted respectively in reinforcement and suppression of 
morphine-induced conditioned place preference in rats (Corrigall and Coen, 1991). These findings indicate the essential role of the central region of the amygdala in the function of addictive drugs, such as morphine and amphetamine. However, the present study showed that amygdala has an effect on nicotine-induced conditioned place preference. On the other hand, dopamine-related behaviors were changed during inhibition of the amygdala.

It is known that conditioned place preference consist a memory and learning part and also a pleasure part. The memory part is related to the dopamine and non-dopamine systems of the brain, while the pleasure part is related to the dopamine system. In addition, hippocampus is a part of brain which involve in learning and memory (Wang, 2010; Adams, 2014; Meftahi et al., 2014; Eslamizade et al., 2015; Meftahi et al., 2015; Pourhashemi et al., 2016). Consequently, given the effect of inhibiting amygdala on decreasing the dopamine-dependent behaviors, it appears that the amygdala has a little effect on the memory part of nicotineinduced place preference and its inhibition primarily affects that part of conditioned place preference, which is related to the mesolimbic system.

\section{CONCLUSION}

In conclusion, is appears that unilateral or bilateral temporary inhibition of the amygdala has little effect on the conditioned place preference induced by nicotine, although it altered dopamine-dependent behaviors significantly in the conditioned animals.

\section{ACKNOWLEDGMENTS}

This study was conducted as part of student thesis project, which was supported by the grant from the Neuroscience Sciences Research Center, Baqiyatallah University of Medical Sciences, Tehran, Iran.

\section{CONFLICT OF INTEREST}

The authors declare no conflict of interest.

\section{REFERENCES}

Asalgoo G, Jahromi GP, Meftahi GH, and Sahraei H. Posttraumatic Stress Disorder (PTSD): Mechanisms and Possible Treatments. Neurophysiol, 2015; 47 (6): 482-489.

Adams JM. The effect of naltrexone on nicotine-induced conditioned place preference in rats. Northern Michigan University The Commons, 2014; 14-17.

Bahari Z, Manaheji H, Dargahi L, Daniali S, Norozian M, Meftahi GH, Sadeghi M. Time Profile of nNOS Expression in the Spinal Dorsal Horn after L5 Spinal Root Transection in Rats. Neurophysiol, 2015;47(4):287-94.

Bahari Z, Manaheji H, Hosseinmardi N, Meftahi GH, Sadeghi M, Danialy S, Noorbakhsh SM.. Induction of spinal long-term synaptic potentiation is sensitive to inhibition of neuronal NOS in 15 spinal nervetransected rats. EXCLI, 2014;13: 251-60.

Bergstron HC, Smith RF, Mollinedo NS, McDonald CG. Chronic nicotine exposure produces lateralized, age-dependent dendritic remodeling in the rodent basolateral amygdala. Synapse, 2010; 64: 754764.

Campeau S, and Davis M. Involvement of subcortical and cortical afferents to the lateral nucleus of the amygdala in fear conditioning measured with fear-potentiated startle in rats trained concurrently with auditory and visual conditioned stimuli. J Neurosci, 1995; 15: 2312-2327.

Carrere M, Alexandre F. A pavlovian model of the amygdala and its influence within the medial temporal lobe. Fronti System Neurosci, 2015; 9: 41 .

Chalabi-Yani D, Sahraei H, Meftahi GH, Hosseini SB, SadeghiGharajehdaghi S, Beig HA, Bourbour Z, Ranjabaran M. Effect of transient inactivation of ventral tegmental area on the expression and acquisition of nicotine-induced conditioned place preference in rats. Iran Biomed Jour, 2015;19(4): 214-219.

Corrigall WA, Coen KM. Selective dopamine antagonists reduce nicotine self-administration. Psychopharmacol, 1991; 104: 171176.

Dalack GW, Healy DJ, Meador-Woodruff JH. Nicotine dependence in schizophrenia: clinical phenomena and laboratory findings. Am J Psychiatry, 1998; 155: 1490-1501.

Dalooei JR, Sahraei H, Meftahi GH, Khosravi M, Bahari Z, Hatef B, Mohammadi A, Nicaeili F, Eftekhari F, Ghamari F, Hadipour M. Temporary amygdala inhibition reduces stress effects in female mice. $J$ Adv Res, 2016;7(5):643-9.

Dani JA. Roles of dopamine signaling in nicotine addiction. Molecular Psychiatry, 2003; 8: 255-256.

Di Chiara G, Imperato A. Drugs abused by humans preferentially increase synaptic dopamine concentrations in the mesolimbic system of freely moving rats. Proc Natl Acad Sci U S A, 1988; 85(14): 5274-8.

Dixon AL, Prior M. Dopamine antagonist modulation of amphetamine response as detected using pharmacological MRI. Neuropharmacol, 2005; 48: 236-245.

Ehteram BZ, Sahraei H, Meftahi GH, Khosravi M. Effect of Intermittent Feeding on Gonadal Function in Male And Female NMRI Mice During Chronic Stress. Braz Arch Biol Technol, 2017; 60: e17160607.

Eslamizade MJ, Saffarzadeh F, Mousavi SM, Meftahi GH, Hosseinmardi N, Mehdizadeh M, Janahmadi M. Alterations in CA1 pyramidal neuronal intrinsic excitability mediated by Ih channel currents in a rat model of amyloid beta pathology. Neurosci, 2015;305:279-92.

Esmaeili MH, Kermani M, Parvishan A, HaghparastA. Role of D1/D2 dopamine receptors in the CA1 region of the rat hippocampus in the rewarding effects of morphine administered into the ventral tegmental area. Behav Brain Res, 2012; 231(1): 111-115.

Ghobadi N, Sahraei H, Meftahi GH, Bananej M, Salehi S. Effect of estradiol replacement in ovariectomized NMRI micein response to acute and chronic stress. Journal of Applied Pharmaceutical Science, 2016; 6(11):176-84. $1548-1549$

Gray JA, Joseph MH. Dopamine's role. Science, 1997; 278:

Holland PC, and Gallagher M. Double dissociation of the effects of lesions of basolateral and central amygdala on conditioned stimulus-potentiated feeding and Pavlovian-instrumental transfer. Eur $J$ Neurosci, 2003;17: 1680-1694.

Hosseini SB, Sahraei H, Mohammadi A, Hatef B, Meftahi GH, Chalabi-Yani D, Alibeig H, Sadeghi-Gharajehdaghi S, Ranjabaran M. Inactivation of the nucl. accumbens core exerts no effect on nicotineinduced conditioned place preference. Neurophysiol, 2015; 47(4): 295301.

Hsu EH, Schroeder JP, Packard MG. The amygdala mediates memory consolidation for an amphetamine conditioned place preference. Behav Brain Res, 2002; 129(1-2): 93-100.

Hyman SE. Addiction: a disease of learning and memory. Am J Psychiatry, 2005;162: 1414-1422. 
Hyman SE, Malenka RC, Nestler EJ. Neural mechanisms of addiction: the role of reward-related learning and memory. Аnnu Rev Neurosci, 2006; 29:565-598.

Ito R, and Hayen A. Opposing toles of nucleus accumbens core and shell dopamine in the modulation of limbic information processing. $J$ Neurosci, 2011; 31(16): 6001-6007.

Kane JK, Hwang Y, Konu O, Loughlin SE, Leslie FM, Li MD. Regulation of Homer and group I metabotropic glutamate receptors by nicotine. Eur J Neurosci, 2005; 21(5): 1145-54.

Kelley AE, Berridge KC. The neuroscience of natural rewards: relevance to addictive drugs. $J$ Neurosci, 2002; 22(9): 3306-11.

Kobiella A, Ulshöfer DE, Vollmert C, Vollstädt-Klein S, Bühler M, Esslinger C, Smolka MN. Nicotine increases neural response to unpleasant stimuli and anxiety in non-smokers. Addict Biol, 2011; 16(2): 285-95.

Kupferschmidt DA, Funk D, Erb S, Lê AD. Age-related effects of acute nicotine on behavioural and neuronal measures of anxiety. Behav Brain Res, 2010; 213(2): 288-92.

Li MD, Kane JK, Wang J, Ma JZ. Time-dependent changes in transcriptional profiles within five rat brain regions in response to nicotine treatment. Brain Res Mol Brain Res, 2004; 132(2): 168-80.

Meftahi G, Ghotbedin Z, Eslamizade MJ, Hosseinmardi N, Janahmadi M. Suppressive Effects of Resveratrol Treatment on The Intrinsic Evoked Excitability of CA1 Pyramidal Neurons. Cell Journal (Yakhteh), 2015;17(3): 532-539.

Meftahi GH, Janahmadi M, Eslamizade MJ. Effects of resveratrol on intrinsic neuronal properties of CA1 pyramidal neurons in rat hippocampal slices. Physiology and Pharmacology. Physiol Pharmacol, 2014; 18 (2), 144-155

Meredith GE. The synaptic framework for chemical signaling in nucleus accumbens. Ann New York Acad Sci, 1999; 877: 140156.

Mohammadian Z, Sahraei H, Meftahi GH, Ali-Beik H. Effects of unilatral- and bi- lateral inhibition of rostral ventral tegmental area and central nucleus of amygdala on morphine-induced place conditioning in male Wistar rat. Clin Exp Pharmacol Physiol, 2016; 1-10. DOI:_10.1111/1440-1681.12715.

Mosher CP, Zimmerman PE, Gothard KM. Response characteristics of basolateral and centromedial neurons in the primate amygdala. $J$ Neurosci, 2010; 30(48): 16197-207.

Motahari AA, Sahraei H, Meftahi GH. Role of nitric oxide on dopamine release and morphine-dependency. Basic Clin Neurosci, 2016; 7(4):283.

Neal L, Benowitz L, Hukkanen and Jacob P. Nicotine chemistry, metabolism, kinetics and biomarkers. Handb Exp Pharmacol, 2009; 192: 29-60.

Nisell M, Nomikos GG, Svensson TH. Nicotine Dependence, Midbrain Dopamine Systems and Psychiatric Disorders. Pharmacology \& Toxicology, 1995;76 (3): 157-162.

Pascual MM, Pastor V, Bernabeu RO. Nicotine-conditioned place preference induced CREB phosphorylation and Fos expression in the adult rat brain. Psychopharmacol (Berl), 2009; 207(1): 57-71.
Paxinos G, Watson D. The Rat Brain in Stereotaxic Coordinates. Acad. Press, New York.1987.

Peto R, Lopez AD, Boreham J, Thun M, Heath C. Mortality from tobacco in developed countries: indirect estimation from national vital statistics. Lancet, 1992;339: 1268-1278.

Pontieri FE, Tanda G, Orzi F, Di Chiara G. Effects of nicotine on the nucleus accumbens and similarity to those of addictive drugs. Nature, 1996; 382( 6588): 255-257.

Pourhashemi SF, Sahraei H, Meftahi GH, Hatef B, Gholipour B. The Effect of 20 Minutes Scuba Diving on Cognitive Function of Professional Scuba Divers. Asian J Sports Med, 2016; 7(3).

Ripley TL, Dunworth SJ, Stephens DN. Consequences of amygdala kindling and repeated withdrawal from ethanol on amphetamine-induced behaviours. Eur J Neurosci,2002; 16(6): 1129-38.

Salín-Pascual RJ, Basañez-Villa E. Changes in compulsion and anxiety symptoms with nicotine transdermal patches in non-smoking obsessive-compulsive disorder patients. Rev Invest Clin, 2003; 55(6): 650-

Shoaib M. Behavioural and biochemical adaptations to nicotine in rats: influence of MK801, an NMDA receptor antagonist. Psychopharmacol, 1997;134: 121-130.

Shoaib M, Benwell MEM, Akbar MT, Stolerman IP, Balfour DJK. Behavioural and neurochemical adaptations to nicotine in rats: influence of NMDA antagonists. Br J Pharmacol, 1994;111: 1073- 1080.

Vlachou S, Markou A. GABAB receptors in reward processes. Adv Pharmacol, 2010; 58: 315-71.

Vollm BA, Cowen PJ, Rolls ET. Methamphetamine activates reward circuitry in drug naive human subjects. Neuropsychopharmacol, 2004; 29: 1715-1722.

Wang LP, Li F, Shen X, Tsien JZ. Conditional knockout of NMDA receptors in dopamine neurons prevents nicotine-conditioned place preference. PLOS One, 2010; 5(1): 1-7.

White NM, Chai SC, Hamdani S. Learning the morphine conditioned cue preference: cue configuration determines effects of lesions. Pharmacol Biochem Behav, 2005; 81(4): 786-96.

Yararbas G, Keser A, Kanit L, Pogun S. Nicotine-induced conditioned place preference in rats: sex differences and the role of mGluR5 receptors. Neuropharmacol, 2010; 58(2):374-82.

Zarrindast MR, Karami M, Sahraei H. Influence of nitric oxide on morphine-induced conditioned place preference in the rat central amygdale. Eur J Pharmacol, 2002; 453(1): 81-9.

Zarindast MR, Rezayof A. Morphin-Induced place preference:Interaction with neurotransmitter systems. Iranian journal of pharmaceutical, 2007; 6: 3-15.

How to cite this article:

Sadeghi-Gharajehdaghi S, Sahraei H, Bahari Z, Meftahi GH, Jahromi GP, Ali-Beik H. Effect of amygdaloid complex inhibition on nicotine-induced conditioned place preference in rats. J App Pharm Sci, 2017; 7 (03): 040-047. 